\title{
Systemetic Investigation of Repeated Administration of Temsirolimus on the Antihyperglycemic Activity of Mifepristone and Risk of Cancer
}

\section{Roohi Jamal, Shubi Jamal* and Suresh DK \\ Department of Pharmacology, Luqman College of Pharmacy, Gulbarga, India}

*Corresponding author: Shubi Jamal, Department of Pharmacology, Luqman College of Pharmacy, Gulbarga, India, Tel: +91-7411845501; Email: getshubi8@yahoo.co.in

\section{Research Article}

Volume 3 Issue 4

Received Date: November 14, 2018

Published Date: November 28, 2018

DOI: $10.23880 /$ apct-16000143

\section{Abstract}

To determine the association between temsirolimus (anticancer) and those of antihyperglycimic agent mifepristone in DXM induced rabbits. Blood glucose levels are estimated up to 24 hrs. Our findings have shown a significant relationship between, dexamethasone treated rabbits pretreatment with temsirolimus $(3.5 \mathrm{mg} / \mathrm{kg})$ for 7 days, which decreased the onset of hypoglycemia i.e. from 2 hour to 1 hour, i.e. $(18.12+.9886$ to $16.15+.7592)$, has significantly enhanced the peak hypoglycemia $(24.91+1.173 \%)$ before treatment $(44.14+.3518 \%)$ after treatment $(p<.001)$, at 8 th hour and duration of hypoglycemia was also significantly enhanced from 18 hrs to more than 24 hrs induced by mifepristone $(9.33 \mathrm{mg} / \mathrm{kg})(17.87+1.202$ to $24.28+1.730),(\mathrm{p}<.001)$. This study indicates that therapeutic drug monitoring has an essential role in therapeutic doses of temsirolimus and antidiabetic drugs when used Simultaneous.

Keywords: Temsirolimus; Mifepristone; DMX

Abbreviations: DM: Diabetes mellitus; GOD: Glucose oxidase; POD: Peroxidase; DMX: Dexamethasone.

\section{Introduction}

An intravenous drugtemsirolimus is used for the treatment of renal cell leiomyoma or Carcinoma. Temsirolimus is likely to result in hyperglycemia and hyperlipaemia. This may result in an increase in the dose of insulin or oral hypoglycemic agents, respectively. Temsirolimus is am TOR inhibitor and has exhibit significantly longer overall survival and progression-free survival for patients with previously untreated renal cell carcinoma with poor-risk features [1]. Correspondingly patients agonize from cushing syndrome with renal cell carcinoma are prescribed with mifepristone and temsirolimus.

Mifepristone is an antihyperglycemic and antiprogesterone drug that is effective in treatment of renal leiomyoma, resulting in fall off leiomyoma size and symptoms [2,3]. Continual administration of small-dosage (5/10 mg daily for a year, $2.5 \mathrm{mg}$ daily for 6 months, etc) $[4,5]$ of mifepristone outcomes in leiomyoma reduction and advancement of symptoms. However, mifepristone leads to cession of uterine carcinoma regrowth reported in many articles [6-9]. When another hormone replacement drug for uterine leiomyoma treatment is stopped, uterine leiomyomas can also re-grow rapidly, and the uterine volume exceed the baseline volume, 


\section{Advances in Pharmacology and Clinical Trials}

which is almost $20 \%$ of uterine volume increased compared with mifepristone treatment [10-15].

Mifepristone medication follows a continual small dosage administration, whereas mifepristone for MTP (Medical Termination of pregnancy) or abortions is often used for a short time and at high dosage. Mifepristone medication shows similar effects as the long-term and low-dose to short term high dose, as in tumor recurrence, which may instigate tumorigenesis (uterine leiomyomas). However, none of this association has been proclaimed till date. Thus, the use of mifepristone can probably increase the risk of renal cell carcinoma. We analyse this fact by reviewing articles on mifepristone.

Whereas mifepristone act as antihyperglycemic agent and prescribed for type 2 diabetes. But studies show that it is associated with risk of renal cell carcinoma. This correlation has driven various campaigns to determine the ant cancerous properties of other antihyperglycemic agents such as metformin, which reduces the cancer risk [16].

In this article we highlight the proposed co-relation of temsirolimus action in cancer with mifepristone and discuss ongoing recent advancement of mifepristone and temsirolimus in cancer. Improved understanding of these issues will increase the chances for successful application of mifepristone with temsirolimus as an inexpensive, well-tolerated, and effective anticancer agent. Temsirolimus is a potent inhibitor of metastatic renal cell carcinoma (mRCC). Thus, it is approved for first-line therapy in high-risk mRCC patients. We discuss the indication and drug-drug interaction of temsirolimus mifepristone treated with DXM in rabbits [17-19].

\section{Materials and Methods}

\section{Study Population}

The studies were carried out in the Department of Pharmacology, which is duly licensed by the CPCSEA (committee for the Purpose of Control and Supervision of Experiments in Animals). All the animals (rabbits) used in the study were procured from Mahavira Enterprises, Hyderabad. Registration number 346/CPCSEA and were housed under standard husbandry conditions in the institutional animal house. Hence, the same may be considered as source of animal procurement in the subsequent sections. A total of 50 rabbits (either sex) were selected for the current study.

- Temsirolimus: The suspensions of Temsirolimus were prepared in $2 \%$ gum acacia to represent $1 \mathrm{mg} / \mathrm{ml}$.

- Rabbits: Obtained from Mahavira Enterprises, Hyderabad.

- Glucose estimation Kit (Pathozyme diagnostic kit).

- Motor and pestle, alcohol, low voltage electric lamp, micropipette $(5-50 \mu \mathrm{l}), 1 \mathrm{ml}$ graduated pipettes, epindr off tubes, thin Aluminium foil, incubator and double distilled water, etc.

- Semi auto analyzer (RMSBCA-201).

\section{Dosage of Mifepristone and Temsirolimus}

Mifepristone- Rabbit Dose: $9.33 \mathrm{mg} / \mathrm{kg}$

Temsirolimus- Rabbit Dos: $0.75 \mathrm{mg} / \mathrm{kg}$

Mifepristone was obtained from Abhishek Chemicals LTD Gujarat. Temsirolimus was obtained from Sigma Aldrich. Temsirolimus (10 mgkg-1, P.0.) suspensions were prepared using $2 \% \mathrm{w} / \mathrm{v}$ gum acacia as suspending agent.

\begin{tabular}{|c|c|c|c|c|}
\hline Study & Pretreatment medication and dose & $\begin{array}{c}\text { Duration of } \\
\text { pretreatment }\end{array}$ & Study drug and dose & $\begin{array}{l}\text { Wash-out } \\
\text { period (w) }\end{array}$ \\
\hline I & $\begin{array}{c}2 \% \mathrm{w} / \mathrm{v} \text { gum acacia dose volume matched with } \\
\text { the average of volume of drug treatments } \\
\text { in the subsequent studies } \mathrm{x} 1\end{array}$ & On day 1 & $\begin{array}{l}2 \% \mathrm{w} / \mathrm{v} \text { gum acacia on the same } \\
\text { day. }\end{array}$ & 1 \\
\hline II & $\begin{array}{c}2 \% \mathrm{w} / \mathrm{v} \text { gum acacia dose volume matched with } \\
\text { the average of volume of drug treatments } \\
\text { in the subsequent studies } \mathrm{x} 1\end{array}$ & On day 1 & $\begin{array}{c}\text { Temsirolimus }(0.75 \mathrm{mg} / \mathrm{kg} \\
\text { B.W.P.0)132, } 0.75 \mathrm{mg} \text { rabbits } / \mathrm{kg} \text {, } \\
\text { p.o. on the same day }\end{array}$ & 1 \\
\hline III & $\begin{array}{c}2 \% \mathrm{w} / \mathrm{v} \text { gum acacia dose volume matched with } \\
\text { the average of volume of drug treatments } \\
\text { in the subsequent studies } \mathrm{x} 1\end{array}$ & On day 1 & $\begin{array}{c}\text { Mifepristone } 18 \mathrm{mg} \text { rats } / \mathrm{kg} \text { or } 9.33 \\
\text { mg rabbits/kg, p.o. on same day. }\end{array}$ & 1 \\
\hline IV & $\begin{array}{l}\text { Temsirolimus } 1.44 \mathrm{mg} / \mathrm{kg} \text { rats } / \mathrm{kg} \text {, p.o. and } \\
0.75 \mathrm{mg} \text { rabbits } / \mathrm{kg} \text {, p.o. }\end{array}$ & $\begin{array}{c}7 \text { days at } 10: 00 \\
\text { am } 7 \text { days at } \\
10: 00 \mathrm{am}\end{array}$ & $\begin{array}{c}\text { Mifepristone } 18 \mathrm{mg} \text { rats } / \mathrm{kg} \text { or } 9.33 \\
\mathrm{mg} \text { rabbits } / \mathrm{kg}, \mathrm{p} . \mathrm{o} \text { on the day } 8 \text { at } \\
11: 00 \mathrm{am}\end{array}$ & 1 \\
\hline
\end{tabular}

Table 1: Experimental Procedure.

Shubi Jamal, et al. Systemetic Investigation of Repeated Administration of Temsirolimus on the Antihyperglycemic Activity of Mifepristone and Risk of Copyright@ Shubi Jamal, et al. Cancer. Adv Pharmacol Clin Trials 2018, 3(4): 000143. 


\section{Advances in Pharmacology and Clinical Trials}

\section{Result and Discussion}

Effect of Vehicle per Se (2\% W/V Gum Acacia Suspension) Administration and Long Term Fasting On Blood Glucose Levels in Healthy Albino Rabbits
Acacia suspension $(2 \% \mathrm{w} / \mathrm{v})$ which has been used as vehicle for administration of the study drugs, by itself did not affect the blood glucose levels in healthy rabbits. Further the long term fasting (38 hrs) which inevitable occurs in these experiments was also did not had any marked influence on the blood sugar levels in these animal species. The results of these findings are compiled in (Table 2) and graphically depicted in (Figure 1).

\begin{tabular}{|c|c|c|c|c|c|c|c|c|c|c|c|c|c|c|}
\hline Time & \multicolumn{9}{|c|}{ Blood Glucose Level (mg \%) } & \multicolumn{5}{c|}{ Percentage Blood Glucose Reduction } \\
\hline HRS & H & B & T & HB & BT & TH & MEAN+SEM & H & B & T & HB & BT & TH & MEAN +SEM \\
\hline 0 & 113 & 102 & 98 & 102 & 110 & 108 & $105.5+2.35$ & - & - & - & - & - & - & - \\
\hline $1 / 2$ & 112 & 101 & 97 & 101 & 109 & 107 & $104.5+2.34$ & 0.88 & 0.98 & 1.02 & 0.98 & 0.909 & 0.92 & $0.9482+.022$ \\
\hline 1 & 114 & 103 & 99 & 99 & 110 & 106 & $105.2+2.47$ & -0.88 & -1 & -1.02 & 2.94 & 0 & 1.85 & $0.3183+.69$ \\
\hline 4 & 112 & 108 & 99 & 98 & 98 & 106 & $103.5+2.45$ & 0.88 & -5.9 & -1.02 & 3.92 & 10.9 & 1.85 & $1.775+2.27$ \\
\hline 6 & 111 & 101 & 98 & 100 & 108 & 108 & $104.3+2.17$ & 1.76 & 0.98 & 0 & 1.96 & 1.81 & 0 & $1.085+.37$ \\
\hline 8 & 113 & 100 & 97 & 101 & 109 & 107 & $104.5+2.50$ & 0 & 1.96 & 1.02 & 0.98 & 0.9 & 0.92 & $0.9633+.25$ \\
\hline 12 & 112 & 100 & 96 & 99 & 111 & 107 & $104.2+2.75$ & 0.88 & 1.96 & 2.04 & 2.94 & -0.9 & 0.92 & $1.307+.54$ \\
\hline 18 & 112 & 102 & 96 & 100 & 109 & 108 & $104.5+2.50$ & -0.88 & 0 & -2.04 & 9.8 & 0.9 & -0.92 & $0.9633+.37$ \\
\hline 24 & 113 & 106 & 97 & 106 & 107 & 106 & $104.3+2.45$ & 0 & -3.9 & 1.02 & -3.92 & 2.7 & 1.8 & $1.115+.29$ \\
\hline
\end{tabular}

Table 2: Blood Glucose Levels after the administration of 2\%Gum acacia suspension in healthy Albino rabbits.
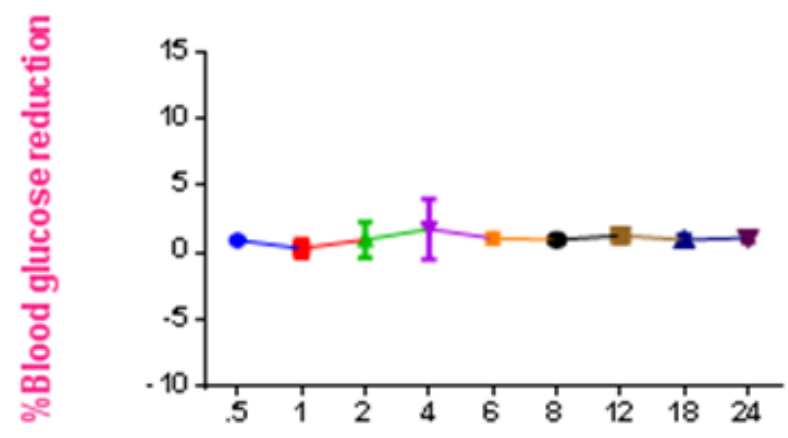

Time in hours

Figure 1: Blood group level after the administration of $2 \%$ gum agacln suspension in healthy albino rabbits.

\section{Influence of Temsirolimus on Blood Glucose Levels in Healthy Albino Rabbits}

In the present study the per se effect of Temsirolimus $(6.75 \mathrm{mg} / \mathrm{kg})$ was assessed. It is evident from the table No. 2 that, treatment of Temsirolimus $(6.75 \mathrm{mg} / \mathrm{kg})$ has no significant influence on the blood glucose levels in healthy albino rabbits. This indicates that Temsirolimus does not possess any hypoglycemic effect. The results of these findings are compiled in (Table 3 ) and graphically depicted in (Figure 2). 


\section{Advances in Pharmacology and Clinical Trials}

\begin{tabular}{|c|c|c|c|c|c|c|c|c|c|c|c|c|c|c|}
\hline Time & \multicolumn{7}{|c|}{ Blood glucose level (mg \%) } & \multicolumn{5}{|c|}{ Percentage blood glucose reduction } \\
\hline HRS & H & B & T & HB & BT & TH & MEAN+SEM & H & B & T & HB & BT & TH & MEAN +SEM \\
\hline 0 & 82 & 78 & 84 & 79 & 85 & 92 & $83.33+2.06$ & - & - & - & - & - & - & - \\
\hline $1 / 2$ & 80 & 76 & 81 & 76 & 83 & 90 & $81+2.12$ & 2.43 & 2.56 & 3.57 & 3.79 & 2.35 & 2.17 & $2.812+0.28$ \\
\hline 1 & 80 & 75 & 79 & 77 & 82 & 90 & $80.50+2.14$ & 2.43 & 3.84 & 5.95 & 2.53 & 3.52 & 2.17 & $3.407+0.57$ \\
\hline 2 & 80 & 76 & 81 & 76 & 83 & 89 & $80.83+1.99$ & 2.43 & 2.56 & 3.57 & 3.79 & 2.35 & 3.26 & $2.993+0.25$ \\
\hline 4 & 79 & 75 & 82 & 77 & 81 & 88 & $81.00+1.57$ & 3.65 & 3.84 & 2.38 & 2.53 & 4.7 & 4.34 & $3.573+0.38$ \\
\hline 6 & 81 & 74 & 83 & 75 & 83 & 87 & $80.50+2.06$ & 1.2 & 5.12 & 1.19 & 5.06 & 2.35 & 5.43 & $3.392+0.82$ \\
\hline 8 & 80 & 76 & 81 & 76 & 82 & 89 & $80.67+1.96$ & 2.43 & 2.56 & 3.57 & 3.79 & 3.52 & 3.26 & $2.202+0.56$ \\
\hline 12 & 79 & 75 & 82 & 77 & 84 & 88 & $80.83+1.95$ & 3.65 & 3.84 & 2.38 & 2.53 & 1.17 & 4.34 & $2.985+.47$ \\
\hline 18 & 80 & 76 & 83 & 74 & 83 & 87 & $80.50+1.97$ & 2.43 & 2.56 & 1.19 & 6.32 & 2.35 & 5.43 & $3.380+0.82$ \\
\hline 24 & 79 & 75 & 80 & 77 & 82 & 90 & $80.58+2.14$ & 3.65 & 3.84 & 4.76 & 2.53 & 3.52 & 2.17 & $3.412+0.38$ \\
\hline
\end{tabular}

Table 3: Blood Glucose Level after the administration of Temsirolimus in healthy albino rabbit.

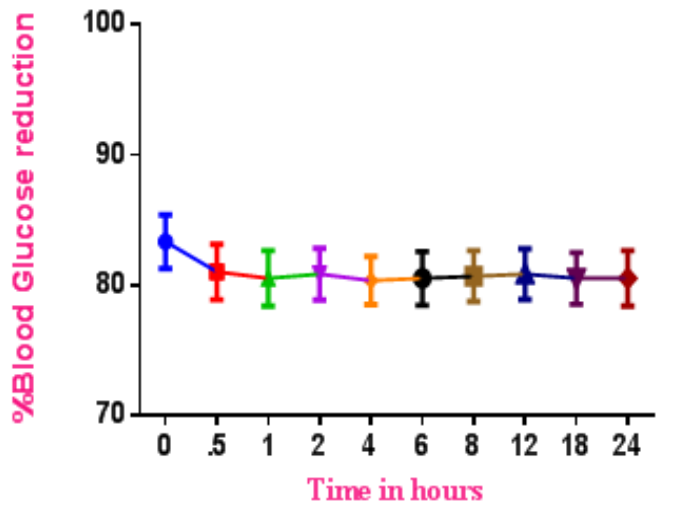

Figure 2: Blood group level after the administration of temsirolimus in healthy rabbits.

\section{Blood Glucose Levels After the Administration of 2\%Gum Acacia Suspension In Rabbits Treated with Dexamethasone}

Effect of Vehicle Per se $(2 \% \mathrm{~W} / \mathrm{V}$ Gum Acacia Suspension)Administration and Long Term Fasting on Blood Glucose Levels in Rabbits treated with dexamethasone Acacia suspension $(2 \% \mathrm{w} / \mathrm{v})$ which has been used as vehicle for administration of the study drugs, by itself did not affect the blood glucose levels in rabbits treated with dexamethasone. Further the long term fasting ( $38 \mathrm{hrs}$ ) which inevitable occurs in these experiments was also did not had any marked influence on the blood sugar levels in these animal species. The results of these findings are compiled in (Table 4) and graphically depicted in (Figure 3). 


\section{Advances in Pharmacology and Clinical Trials}

\begin{tabular}{|c|c|c|c|c|c|c|c|c|c|c|c|c|c|c|}
\hline Time & \multicolumn{1}{|c|}{ Blood Glucose Level (mg\%) } & \multicolumn{4}{c|}{ Percentage Blood Glucose Reduction } \\
\hline HRS & H & B & T & HB & BT & TH & MEAN+SEM & H & B & T & HB & BT & TH & MEAN +SEM \\
\hline 0 & 158 & 149 & 162 & 156 & 164 & 170 & $159.8+2.94$ & - & - & - & - & - & - & - \\
\hline $1 / 2$ & 157 & 147 & 159 & 154 & 163 & 169 & $159.0+3.09$ & 0.63 & 1.34 & 1.85 & 1.28 & 0.6 & 0.58 & $1.047+0.21$ \\
\hline 1 & 156 & 148 & 160 & 155 & 161 & 165 & $157.5+2.40$ & 1.26 & 0.67 & 1.23 & 0.64 & 1.82 & 2.94 & $1.427+0.35$ \\
\hline 2 & 157 & 147 & 159 & 154 & 162 & 168 & $157.8+2.91$ & 0.63 & 1.34 & 1.85 & 1.28 & 1.21 & 1.17 & $1.247+0.15$ \\
\hline 4 & 156 & 147 & 160 & 153 & 162 & 168 & $157.7+2.99$ & 1.26 & 1.34 & 1.23 & 1.92 & 1.21 & 1.17 & $1.355+0.11$ \\
\hline 6 & 156 & 147 & 160 & 153 & 162 & 169 & $157.8+3.11$ & 1.26 & 1.34 & 1.23 & 1.92 & 1.21 & 0.58 & $1.257+0.17$ \\
\hline 8 & 157 & 146 & 161 & 156 & 164 & 167 & $158.5+3.01$ & 0.63 & 2.01 & 0.62 & 0 & 0 & 1.76 & $8362+0.35$ \\
\hline 12 & 158 & 148 & 153 & 155 & 165 & 165 & $157.3+2.76$ & 0.000 & 0.67 & 5.55 & 0.64 & -0.6 & 2.94 & $1.53+0.94$ \\
\hline 18 & 160 & 145 & 158 & 157 & 160 & 168 & $158.0+3.04$ & -1.26 & 2.68 & 2.46 & -0.64 & 2.43 & 1.176 & $1.141+0.70$ \\
\hline 24 & 156 & 146 & 161 & 154 & 162 & 169 & $158+3.21$ & 1.26 & 2.01 & 0.61 & 1.28 & 1.21 & 0.58 & $1.158+0.21$. \\
\hline
\end{tabular}

Table 4: Blood Glucose Levels after the administration of $2 \%$ Gum acacia suspension in rabbits treated with Dexamethasone.

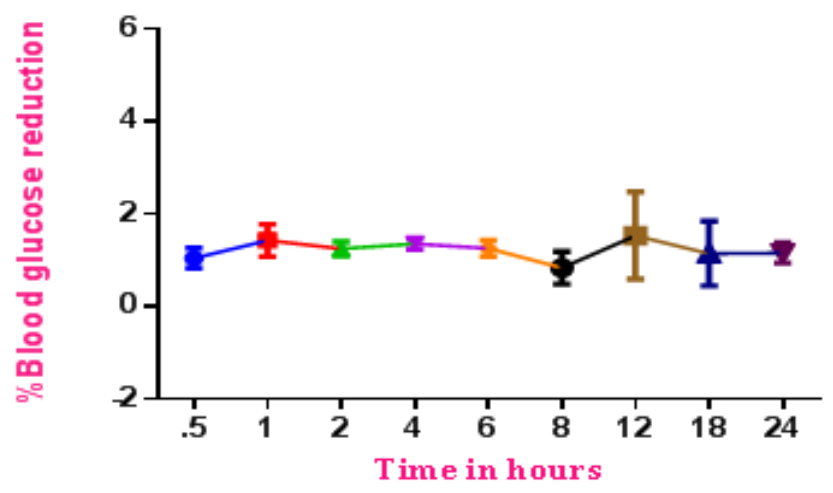

Figure 3: Blood group level after the administration of $2 \%$ gum acacia suspension in rabbits treated with dexamethasone.

Effect of Temsirolimus Administration and Long Term Fasting on Blood Glucose Levels in Rabbits treated with Dexamethasone

Temsirolimus administration, by itself did not affect the blood glucose levels in rabbits treated with dexamethasone. Further the long term fasting (38 hrs) which inevitable occurs in these experiments was also did not had any marked influence on the blood sugar levels in these animal species. The results of these findings are compiled in (Table 5) and graphically depicted in (Figure 4). 


\section{Advances in Pharmacology and Clinical Trials}

\begin{tabular}{|c|c|c|c|c|c|c|c|c|c|c|c|c|c|c|}
\hline Time & \multicolumn{1}{|c|}{ Blood Glucose Level (mg\%) } & \multicolumn{4}{c|}{ Percentage Blood Glucose Reduction } \\
\hline HRS & H & B & T & HB & BT & TH & MEAN+SEM & H & B & T & HB & BT & TH & MEAN +SEM \\
\hline 0 & 158 & 164 & 160 & 159 & 145 & 170 & $159.3+3.383$ & - & - & -- & - & - & - & - \\
\hline $1 / 2$ & 159 & 156 & 161 & 159 & 148 & 165 & $158.0+2.338$ & -0.63 & 4.87 & -0.62 & 0 & -2.06 & 2.94 & $0.7500+1.065$ \\
\hline 1 & 156 & 157 & 156 & 156 & 150 & 168 & $157.2+2.400$ & 1.26 & 4.26 & 2.5 & 1.88 & -3.44 & 1.17 & $1.272+1.049$ \\
\hline 2 & 155 & 159 & 157 & 158 & 149 & 169 & $157.8+2.664$ & 1.89 & 3.04 & 1.87 & 0.62 & -2.75 & 0.58 & $0.8750+0.8165$ \\
\hline 4 & 157 & 162 & 159 & 152 & 151 & 167 & $158.0+2.477$ & 0.632 & 1.21 & 0.63 & 4.4 & -4.13 & 1.7 & $0.7395+1.130$ \\
\hline 6 & 154 & 161 & 158 & 156 & 152 & 168 & $158.2+2.344$ & 2.53 & 1.82 & 1.25 & 1.88 & -4.8 & 1.17 & $0.6417+1.107$ \\
\hline 8 & 156 & 163 & 156 & 157 & 149 & 172 & $158.8+3.198$ & 1.26 & 0.66 & 2.5 & 1.25 & -2.7 & -1.17 & $0.3000+0.7736$ \\
\hline 12 & 158 & 160 & 161 & 158 & 142 & 170 & $158.2+3.710$ & 0 & 2.4 & -0.62 & 0.62 & 2.06 & 0 & $0.7433+0.4986$ \\
\hline 18 & 157 & 164 & 159 & 156 & 144 & 167 & $157.8+3.667$ & 0.632 & 0 & 0.63 & 1.88 & 0.68 & 1.7 & $.9195+.2946$ \\
\hline 24 & 160 & 162 & 165 & 157 & 143 & 169 & $159.3+3.676$ & -1.26 & 1.21 & -3.12 & 1.25 & 1.37 & 0.58 & $0.0050+0.7430$ \\
\hline
\end{tabular}

Table 5: Blood Glucose Levels after the administration of Temsirolimus in rabbits treated with Dexamethasone.

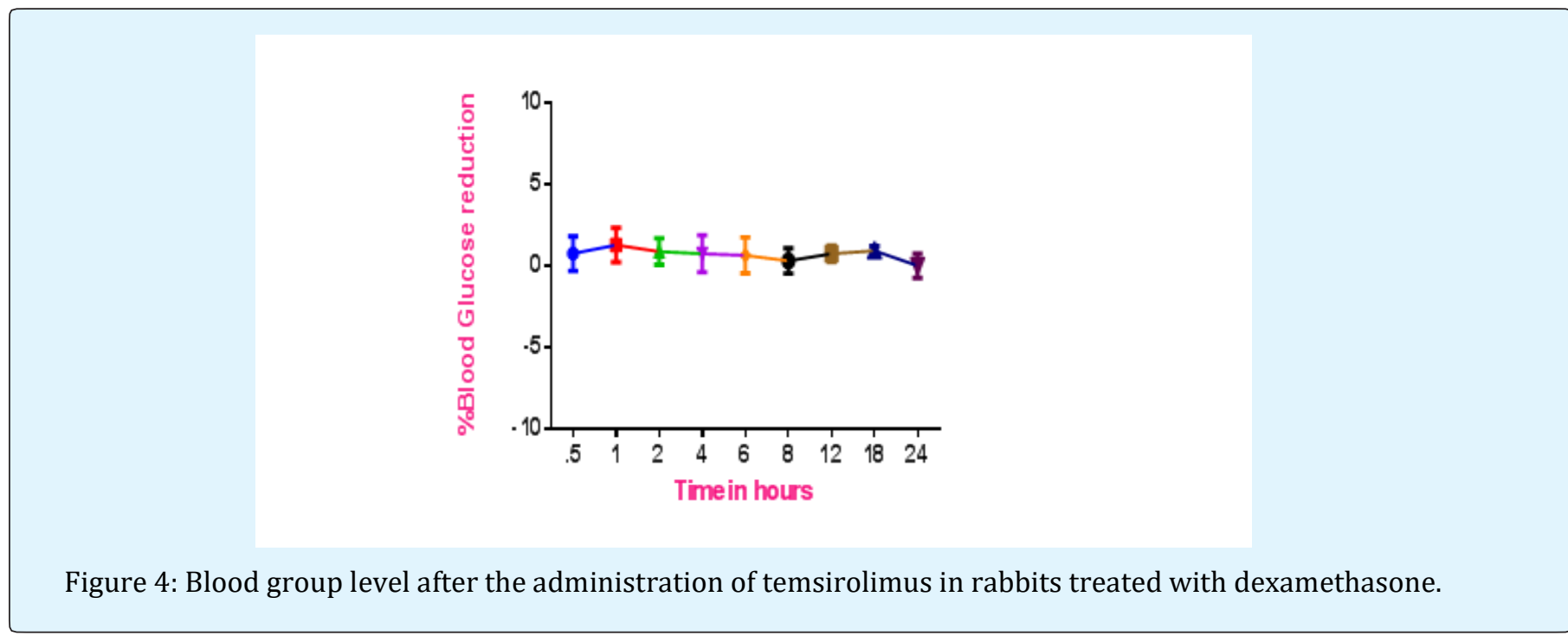

\section{Effect of Temsirolimus Pre-Treatment on Hypoglycemic Effect of Mifepristone in Rabbits treated with Dexamethasone}

Onset of hypoglycemia the time taken to reduce blood glucose level to the extent of 15-20\%), duration of hypoglycemia the time duration in which more than $20 \%$ reduction in blood glucose level is maintained) and peak hypoglycemia were the parameters considered for the evaluation of influence on mifepristone induced hypoglycemia. Present study showed that.in dexamethasone treated rabbits pretreatment with Temsirolimus $(3.5 \mathrm{mg} / \mathrm{kg})$ for 7 days has decreased the onset of hypoglycemia i.e. from 2 hour to 1 hour, i.e. $(18.12+.9886$ to $16.15+.7592)$, has significantly enhanced the peak hypoglycemia $(24.91+1.173 \%)$ before treatment to $(44.14+.3518 \%)$ after treatment, $(\mathrm{p}<.001)$ at $8^{\text {th }}$ hour , and duration of hypoglycemia was also significantly enhanced from $18 \mathrm{hrs}$ to more than $24 \mathrm{hrs}$ induced by mifepristone $(9.33 \mathrm{mg} / \mathrm{kg})(17.87+1.202$ $24.28+1.730),(\mathrm{p}<.001)$. The results of these findings are compiled in (Table 6) and (Table 7) and graphically depicted in (Figure 5). 


\section{Advances in Pharmacology and Clinical Trials}

\begin{tabular}{|c|c|c|c|c|c|c|c|c|c|c|c|c|c|c|}
\hline Time & \multicolumn{10}{|c|}{ Blood Glucose Level (mg\%) with Mifepristone } & \multicolumn{7}{|c|}{ Blood Glucose Level (mg\%) with Mifepristone + } \\
Temsirolimus \\
\hline HRS & H & B & T & HB & BT & TH & MEAN+SEM & H & B & T & HB & BT & TH & MEAN +SE \\
\hline 0 & 148 & 152 & 158 & 165 & 146 & 180 & $158.2+5.205$ & 221 & 150 & 184 & 228 & 230 & 219 & $205.30+13$ \\
\hline $1 / 2$ & 146 & 151 & 156 & 164 & 146 & 179 & $157.0+5.203$ & 219 & 148 & 182 & 224 & 229 & 216 & $203.00+12.92$ \\
\hline 1 & 144 & 148 & 151 & 162 & 145 & 174 & $154.0+4.796$ & 179 & 128 & 156 & 195 & 194 & 180 & $172.00+10.52$ \\
\hline 2 & 120 & 121 & 134 & 138 & 115 & 150 & $129.7+5.432$ & 165 & 120 & 145 & 182 & 179 & 169 & $160.0+9.619$ \\
\hline 4 & 118 & 118 & 130 & 129 & 112 & 148 & $125.8+5.269$ & 158 & 102 & 121 & 160 & 150 & 149 & $140.00+9.504$ \\
\hline 6 & 117 & 116 & 128 & 127 & 110 & 145 & $123.8+5.082$ & 140 & 98 & 119 & 141 & 139 & 138 & $129.20+7.08$ \\
\hline 8 & 109 & 111 & 120 & 121 & 108 & 145 & $119.0+5.675$ & 125 & 83 & 105 & 125 & 129 & 121 & $114.70+7.2$ \\
\hline 12 & 114 & 120 & 131 & 126 & 115 & 151 & $126.2+5.630$ & 134 & 91 & 118 & 140 & 144 & 142 & $128.20+8.368$ \\
\hline 18 & 116 & 124 & 136 & 131 & 121 & 152 & $130.0+5.273$ & 145 & 105 & 124 & 146 & 156 & 161 & $139.50+8.6$ \\
\hline 24 & 129 & 138 & 142 & 145 & 128 & 155 & $139.5+4.169$ & 165 & 121 & 130 & 162 & 181 & 172 & $155.20+9.823$ \\
\hline
\end{tabular}

Table 6: Blood Glucose Levels with Mifepristone before and after Temsirolimus treatment in Rabbits treated with dexamethasone.

\begin{tabular}{|c|c|c|c|c|c|c|c|c|c|c|c|c|c|c|}
\hline Time & \multicolumn{3}{|c|}{ \% Blood Glucose Levels with Mifepristone } & \multicolumn{5}{c|}{ \% Blood Glucose Levels with } \\
\hline HRS & H & B & T & HB & BT & TH & MEAN+SEM & H & B & T & HB & BT & TH & MEAN +SEM \\
\hline 0 & - & - & - & - & - & - & - & - & - & - & - & - & - & - \\
\hline $1 / 2$ & 1.35 & 0.65 & 1.26 & 0.6 & 0 & 0.55 & $0.7350+0.2044$ & 0.9 & 1.3 & 1.08 & 1.75 & 0.4 & 1.36 & $1.132+.1875$ \\
\hline 1 & 2.7 & 2.63 & 4.43 & 1.81 & 0.68 & 3.33 & $2.597+.5229$ & 19 & 14.7 & 15.2 & 14.47 & 15.65 & 17.88 & $16.150+.759$ \\
\hline 2 & 18.91 & 20.39 & 15.18 & 16.36 & 21.2 & 16.66 & $18.12+0.9886$ & 25.33 & 20 & 21.2 & 20.17 & 22.17 & 22.83 & $21.950+.8123^{*}$ \\
\hline 4 & 20.27 & 22.36 & 17.72 & 21.81 & 22.6 & 17.77 & $20.42+0.9089$ & 28.5 & 32 & 34.2 & 29.82 & 34.78 & 31.96 & $31.880+.993^{* *}$ \\
\hline 6 & 20.94 & 23.68 & 18.98 & 23.03 & 24.5 & 18.88 & $21.67+0.9908$ & 36.65 & 34.7 & 35.3 & 38.15 & 39.56 & 36.98 & $36.890+.735^{* *}$ \\
\hline 8 & 26.34 & 26.97 & 24.05 & 26.66 & 26 & 19.44 & $24.91+1.173$ & 43.43 & 44.7 & 42.9 & 45.17 & 43.91 & 44.74 & $44.140+.351^{* *}$ \\
\hline 12 & 22.97 & 21.05 & 17.08 & 23.63 & 21.2 & 16.11 & $20.35+1.259$ & 39.36 & 39.3 & 35.9 & 38.59 & 37.39 & 35.15 & $37.610+.733^{* * *}$ \\
\hline 18 & 21.62 & 18.42 & 13.92 & 20.6 & 17.1 & 15.55 & $17.87+1.202$ & 34.38 & 30 & 32.6 & 35.96 & 32.17 & 26.48 & $31.930+1.36^{* *}$ \\
\hline 24 & 12.8 & 9.21 & 10.12 & 12.12 & 12.3 & 13.88 & $11.74+0.7120$ & 25.33 & 19.3 & 29.3 & 28.94 & 21.3 & 21.46 & $24.280+1.73^{* *}$ \\
\hline
\end{tabular}

Table 7: Percentage Blood Glucose Levels with Mifepristone before and after Temsirolimus treatment in rabbits treated with Dexamethasone.

Significant at $\mathrm{p}<0.05$; $^{* *}$ Highly significant at $\mathrm{p}<0.01$; ${ }^{* * *}$ Very highly significant at $\mathrm{p}<0.001$

* Represents the comparison of Mifepristone with Mifepristone +Temsirolimus interaction 


\section{Advances in Pharmacology and Clinical Trials}

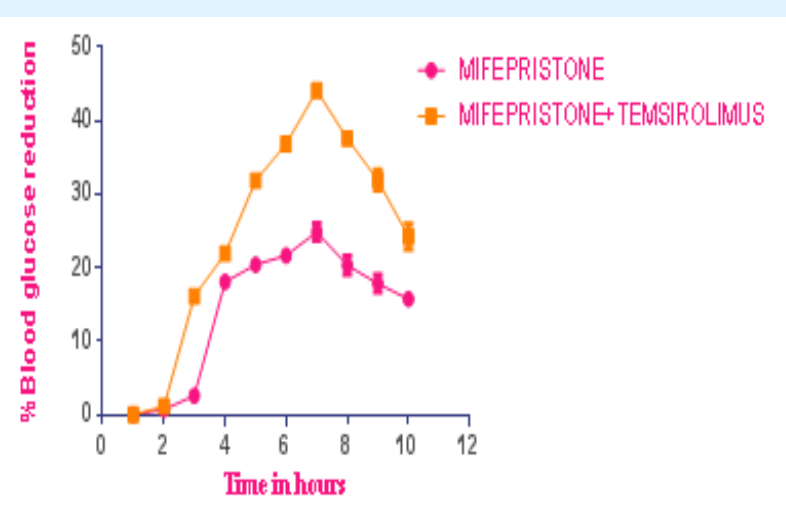

Figure 5: Percentage blood Glucose levels with Mifepristone before and after Temsirolimus treatment in rabbits treated with dexamethasone.

\section{Discussion}

Sometimes it is necessary to administer more than one drug into a patient for treating a single disease, or the multiple diseases in him. When they are used concomitantly there is a possibility that drug-drug interaction may develop that is one of the drugs may alter the effect of the other drug or effect of both drugs are altered, such that alteration of the dose and frequency of one of the drugs/both the drugs may be necessary. These types of drug-drug interactions occur more frequently in whom multiple drugs are used chronically. In all such conditions it is a needed to make the attempts to readjust the dose and frequency of administration of any one or both the drugs. The type and extent of interaction are necessary to understand for readjusting the doses. There are certain diseases for which chronic treatment is needed. If two or more diseases are present in a single patient, the drugs for both the diseases are used concomitantly for a chronic period.

Hyperglycemia a form of diabetes due to deficient insulin action, which is tenacious by both the capacity to secrete insulin from pancreatic Beta- cells and insulin action in peripheral insulin- sensitive tissue being liver and muscle, needs lifelong treatment. As per literature review Hypertension is more prone to occur with hyperglycemic patients. If a patient is suffering from diabetes mellitus as well as hypertension, he has to use anti diabetic drug Sitaglptin or mifeperistone and an anticancerous agent like Temsorlimus. In such precedents, there is an occurrence of drug interactions. Our pilot study has concluded that drug interactions between
Temsirolimus and mifepristone occurred, when administered simultaneously at therapeutic doses. However, the therapeutic dose was found to be influenced the anti-diabetic effect accordingly. During hyperglycemia regulation of blood glucose level is immensely needed and important. If drug potentially affects the ant diabetic agent, severe diabetes might be developed or if it inactivates the doses may be ineffective. Temsirolimus has the property to inhibit the isozyme CYP-450, and effected by CYP-3A4. However, there may be a chance of drug interaction between metabolized drug by theses enzymes and temsirolimus. The present study concentrates on drug interaction between anticancer us and antihyperglycemic oral drugs. These classes of drugs assessed in normoglycemic rabbits and dexamethasone induced hyperglycemic rabbits.

Whereas in Dexamethasone treated rabbits, pretreatment with temsirolimus $(6.75 \mathrm{mg} / \mathrm{kg})$ for 7 days has decreased the onset of hypoglycemia i.e. from 2 hour to 1 hour, $(18.28+1.141$ to $16.67+1.347)$, significantly enhanced the peak hypoglycemia $(24.13+.6417 \%)$ before treatment to $(45.62+2.845 \%)$ after treatment, $(\mathrm{p}<.001)$ at $8^{\text {th }}$ hour ,and duration of hypoglycemia was enhanced from $18 \mathrm{hrs}$ to more than $24 \mathrm{hrs}(10.47+1.538$ to $23.27+2.717$ ) induced by Mifepristone.

It was observed that Pre-treatment with Temsirolimus (6.75 $\mathrm{mg} / \mathrm{kg}$ for seven days) has significantly altered all the parameters of hypoglycaemia induced by Mifepristone an antihyperglycemic agent used in cushing syndrome. Howere there is a report that carnivorus animals (rats) and herbivorus animals 


\section{Advances in Pharmacology and Clinical Trials}

(rabbits) responds differentially to insulin lack hence, in third phase an attempt was made to analyse the influence of pretreatment of Temsirolimus on hypoglycaemia induced by Mifepristone in normoglycaemic and Dexamethasone induced rabbits. Results of these experiments have indicated that in healthy rabbits. Pretreatment with Temsirolimus $(3.5 \mathrm{mg} / \mathrm{kg}$ for seven days), has significantly altered the onset of hypoglycemia i.e. $(18.34+.9509$ to $21.08 \pm .6378, \mathrm{p}<0.001)$ at 2 nd hour, significantly enhanced the peak hypoglycemia $(27.90+2.718 \%)$ before treatment to $(41.47+.5881 \%)$ after treatment, $(\mathrm{p}<0.001)$ at $4^{\text {th }}$ hour. and duration of hypoglycemia was also significantly enhanced from about 12 hrs to more than 24 hours.

The results in diabetic animals are indicating that drug-drug interaction occur even in pathophysiological conditions It was observed in all the three types of animals i.e. healthy rabbits, dexamethasone induced rabbits, diabetic rabbits drug interaction, Occur, when temsirolimus is administered concomitantly with mifepristone. Since the Temsirolimus has not shown significant effect on onset of hypoglycaemia, it may be inferredth at Temsirolimus do not interefere with absorption of oral anti diabetic agents. However, Temsirolimus have significantly enhanced the hypoglycemia in both induced by Mifepristone. This may be due to fact that Temsirolimusmainly inhibit and CYP3A 4 , which is involved in the metabolism of Mifepristone the above observations suggest that the interation between Temsirolimus and Mifepristone are very intense and it demands their adjustment of dose and frequency of oral anti diabetic agents when they are used concomitantly. The results of the whole study are summarized in (Table 8).

\begin{tabular}{|c|c|c|c|c|c|c|c|c|}
\hline Sr.no. & Treatment & $\begin{array}{c}\text { Dose } \\
\mathbf{m g} / \mathbf{k g}\end{array}$ & $\begin{array}{c}\text { More than 15 \% } \\
\text { Onset of } \\
\text { reduction in } \\
\text { blood glucose } \\
\text { maintained for } \\
\text { (hrs) }\end{array}$ & $\begin{array}{c}\text { Duration } \\
\text { of action }\end{array}$ & $\begin{array}{c}\text { Peak effect } \\
\text { seen at time } \\
\text { 't' (Hrs.) }\end{array}$ & $\begin{array}{c}\text { Maximum \% } \\
\text { blood glucose } \\
\text { reduction }\end{array}$ & Inference \\
\hline 1 & Temsirolimus & 3.5 & - & - & - & - & $\begin{array}{c}\text { Temsirolimus has } \\
\text { not shown any } \\
\text { hypoglycemic } \\
\text { effect. }\end{array}$ \\
\hline 2 & $\begin{array}{c}\text { Mifepristone } \\
\text { (Group-II) }\end{array}$ & 9.33 & 2 & 18 & 16 & 8 & $24.91+1.17$ & $\begin{array}{c}\text { Onset of action is } \\
\text { decreased, } \\
\text { duration of } \\
\text { hypoglycemia and } \\
\text { peak effect were } \\
\text { enhanced. }\end{array}$ \\
\hline 3 & $\begin{array}{c}\text { Temsirolimus+ } \\
\text { Mifepristone } \\
\text { (Group-II) }\end{array}$ & 1 hours & $>24$ hours & $>24$ hours & 8 hours & $44.14+.35$ & \\
\hline
\end{tabular}

Table 8: Effect of Temsirolimus treatment on hypoglycemic activity to Mifepristone in Dexamethasone treated rabbits.

\section{Conclusion}

The inference of present study is, during concurrent treatment of diabetes and cancer a drug interaction or an isozyme drug metabolite interaction may be transpire. Lead to increase or decresae in tumerogenesis or carcinoma. Therefore, a therapeutic drug monitoring is essential so as to readjust dose and frequency of administration of these drugs, when they are used concominantly to avoid the patients from severe hypoglycaemia or renal cell carcinoma.

\section{Acknowledgement}

Suresh D.K have developed the concept and designed this research work, while RazaHasan assisted in experimental procedure and Mahesh $\mathrm{S}$ performed the statistical analysis. The author is thankful to management committee, vocational education Society (V.E.S), Luquman College of Pharmacy, Gulberga for providing all the facilities to carry out this research work. We also thank to sigma Aldrich for providing Mifepriston and Temsiorlimus. 


\section{Advances in Pharmacology and Clinical Trials}

\section{References}

1. Hudes G, Carducci M, Tomczak P, Dutcher J, Figlin R, et al. (2007) Temsirolimus, interferon alfa, or both for advanced renal-cell carcinoma. N Engl J Med 356(22): 2271-2281.

2. Eisinger SH, Fiscella J, Bonfiglio T, Meldrum S, Fiscella K (2009) Open-label study of ultra low-dose mifepristone for the treatment of uterine leiomyomata. Eur J Obstet Gynecol Reprod Biol 146: 215-218.

3. Shen $Q$, Hua $Y$, Jiang $W$, Zhang $W$, Chen $M$, et al. (2013) Effects of mifepristone on uterine leiomyoma in premenopausal women: a meta-analysis. Fertil Steril 100(6): 1722-1726.

4. Eisinger SH, Bonfiglio T, Fiscella K, Meldrum S, Guzick DS (2005) Twelve-month safety and efficacy of lowdose mifepristone for uterine myomas. J Minim Invasive Gynecol 12(3): 227-233.

5. Okolo S (2008) Incidence aetiology and epidemiology of uterine fibroids. Best Pract Res Clin Obstet Gynaecol 22(4): 571-588.

6. Ishikawa H, Ishi K, Serna VA, Kakazu R, Bulun SE, et al. (2010) Progesterone is essential for maintenance and growth of uterine leiomyoma. Endocrinology 151: 2433-2442.

7. Reed SD, Cushing-Haugen KL, Daling JR, Scholes D, Schwartz SM (2004) Postmenopausal estrogen and progestogen therapy and the risk of uterine leiomyomas. Menopause 11(2): 214-222.

8. Van Voorhis BJ, Romitti PA, Jones MP (2002) Family history as a risk factor for development of uterine leiomyomas. Results of a pilot study. J Reprod Med 47(8): 663-669.

9. Sundermann AC, Velez Edwards DR, Bray MJ, Jones SH, Latham SM, et al. (2017) Leiomyomas in
Pregnancy and Spontaneous Abortion: A Systematic Review and Meta-analysis. Obstet Gynecol 130(5): 1065-1072.

10. Stein K, Ascher-Walsh C (2009) A comprehensive approach to the treatment of uterine leiomyomata. Mt Sinai J Med 76(6): 546-556.

11. Parker WH (2007) Etiology, symptomatology, and diagnosis of uterine myomas. Fertil Steril 87(4): 725736.

12. Tang OS, Ho PC (2006) Clinical applications of mifepristone. Gynecol Endocrinol 22(12): 655-659.

13. Sun Y, Fang M, Davies H, Hu Z (2014) Mifepristone: a potential clinical agent based on its anti-progesterone and anti-glucocorticoid properties. Gynecol Endocrinol 30(3): 169-173.

14. Quinn BJ, Kitagawa H, Memmott RM, Gills JJ, Dennis PA (2013) Repositioning metformin for cancer prevention and treatment Brendan. Trends Endocrinol Metab 24(9): 469-480.

15. Wang C (2012) History of the Chinese family planning program: 1970-2010. Contraception 85: 563-569.

16. Hee-Kyung Joh, Walter C Willett, Eunyoung Cho (2011) Type 2 Diabetes and the Risk of Renal Cell Cancer in Women. Diabetes Care 34(7): 1552-1556.

17. Calle EE, Kaaks R (2004) Overweight Obesity and cancer: epidemiological evidence and proposed mechanisms. Nat Rev Cancer 4(8): 579-591.

18. Xue F, Michels KB (2007) Diabetes, metabolic syndrome, and breast cancer: a review of the current evidence. Am J Clin Nutr 86(3): 823-835.

19. Zhou JR, Blackburn GL, Walker WA (2007) Symposium introduction: metabolic syndrome and the onset of cancer. Am J Clin Nutr 86: 817-819. 